\title{
Special Issue Acknowledgments
}

he guest editors and authors would like to thank the sponsors of this special issue. The USDA-Natural Resources Conservation Service (NRCS)-Ecological Sciences Division, the USDA-NRCS-Soil Survey Division, the USDA-Agricultural Research Service (ARS)-Jornada Experimental Range, and the USDA-ARS-Natural L Resources and Sustainable Agriculture Systems provided support for this special issue.

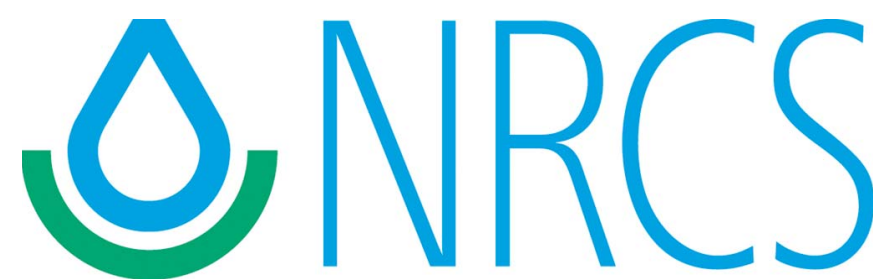

Since 1935, the NRCS of USDA has provided leadership in a partnership effort to help America's private land owners and managers conserve their soil, water, and other natural resources. NRCS employees provide sound, science-based technical assistance tailored to farmers' and ranchers' specific needs. Participation in government conservation programs is voluntary. The USDA is an equal opportunity provider and employer. For more information see http://www.nrcs.usda.gov and http://www.usda.gov.

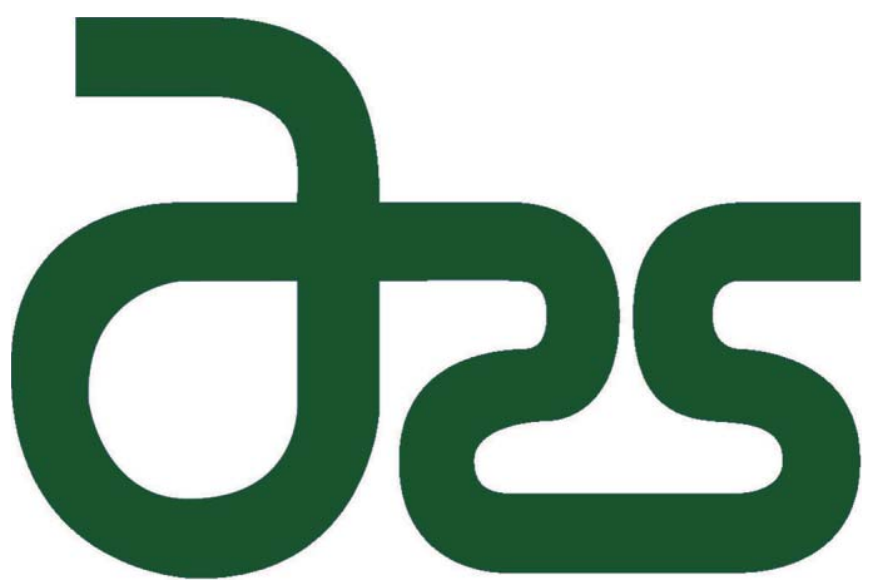

ARS is the USDA's chief scientific research agency. ARS conducts research to develop and transfer solutions to agricultural problems of high national priority. The Natural Resources and Sustainable Agricultural Systems national programs support researchers in developing technologies and strategies for stewardship of the diverse agricultural mosaic.

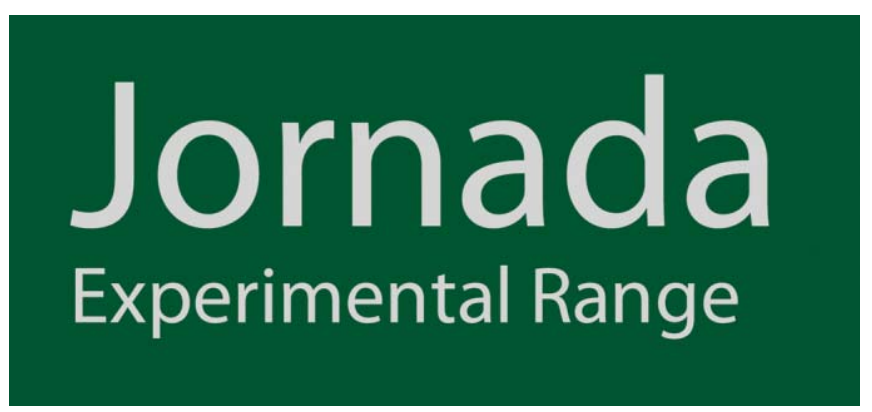

The goal of the Jornada Experimental Range is to develop ecologically based monitoring, restoration, and management technologies for arid environments. 